\title{
Risk factors for unplanned reintubation caused by acute airway compromise after general anesthesia: a case-control study
}

\author{
Si Chen ${ }^{1}$, Yuelun Zhang ${ }^{2}$, Lu Che ${ }^{1}$, Le Shen ${ }^{1 *}$ (D) and Yuguang Huang ${ }^{1}$
}

\begin{abstract}
Background: This study aimed to identify the risk factors and evaluate the prognosis of unplanned reintubation caused by acute airway compromise (AAC) after general anesthesia.

Methods: This case-control study included surgical patients who underwent unplanned reintubation in the operating room and postanesthesia care unit after general anesthesia between January 1, 2014, and December 31, 2018. Cases due to AAC were matched 1:4 with randomly selected controls.

Results: A total of 123,068 patients were included, and reintubation due to AAC was performed in 36 patients (approximate incidence 0.03\%). Univariable analysis revealed that male sex, age $>65$, ASA physical status 3, sepsis, heart disease history, cerebral infarction history, Cormack Lehane grade, surgery type, fresh frozen plasma infusion, increased intubation duration, white blood cell count, and creatinine clearance rate were related to AAC-caused unplanned reintubation. Multivariable analysis revealed that age $>65(\mathrm{OR}=7.50,95 \% \mathrm{Cl} 2.47-22.81, P<0.001)$, ASA physical status $3(\mathrm{OR}=6.51,95 \% \mathrm{Cl} 1.18-35.92, P=0.032)$, head-neck surgery $(\mathrm{OR}=4.94,95 \% \mathrm{Cl} 1.33-18.36, P=$ $0.017)$ or thoracic surgery $(\mathrm{OR}=12.56,95 \% \mathrm{Cl} 2.93-53.90, P<0.001)$ and a high fluid load $(\mathrm{OR}=3.04,95 \% \mathrm{Cl} 1.16-$ 7.99, $P=0.024$ ) were associated with AAC-caused unplanned reintubation. AAC-caused unplanned reintubation patients had longer postoperative hospital $(\mathrm{OR}=5.26,95 \% \mathrm{Cl} 1.57-8.95, P<0.001)$ and intensive care unit days $(\mathrm{OR}=3.94,95 \% \mathrm{Cl} 1.69-6.18, P<0.001)$.
\end{abstract}

Conclusions: Age $>65$, ASA physical status 3, head-neck or thoracic surgery and high fluid load were found to be associated with AAC-caused unplanned reintubation.

Keywords: Airway, Complications, Extubation, General anesthesia, Prognosis

\section{Background}

Unplanned reintubation refers to intubation after failed extubation. It is a significant adverse event after general anesthesia with tracheal intubation and is often related to postoperative pneumonia, tracheotomy, prolonged stays in the hospital or intensive care unit (ICU), increased hospital costs and mortality $[1,2]$.

\footnotetext{
* Correspondence: pumchshenle@aliyun.com

'Department of Anesthesiology, Peking Union Medical College Hospital, Chinese Academy of Medical Science \& Peking Union Medical College, Beijing 100730, China

Full list of author information is available at the end of the article
}

The reasons for unplanned reintubation can vary from a patient's unstable physical condition [3] to surgical indications, accidental removal of the endotracheal tube and others. Many studies have identified risk factors for reintubation without analysing the causes. Some studies classified the cause of reintubation as airway or nonairway, but most of these studies focused on ICU patients $[4,5]$. To our knowledge, no previous study has investigated the risk factors and prognosis of postoperative unplanned reintubation caused by acute airway compromise (AAC) after classifying the cases by cause. 
The purpose of this study was to evaluate the risk factors and prognosis of unplanned reintubation caused by AAC in surgical patients after general anesthesia.

\section{Methods}

\section{Study design and setting}

This investigation was a retrospective, case-control study approved by the Peking Union Medical College (PUMC) Hospital Institutional Review Board (S-K745, April 25th, 2019). The requirement for written informed consent was waived by the institutional review board. The basic information of the surgical patients who underwent unplanned reintubation between January 1, 2014, and December 31, 2018, in the PUMC hospital operating room and postanaesthetic care unit (PACU) was obtained from the adverse-event reporting system. All the data related to the patient, anesthesia and operation were collected from the anesthetic recording system and Hospital Information System of PUMC Hospital. This manuscript adheres to the applicable Strengthening the Reporting of Observational studies in Epidemiology (STROBE) guidelines.

\section{Participants}

All surgical cases involving unplanned reintubation in the operating room or PACU from January 1, 2014, to December 31, 2018, were extracted from the adverseevent system and then analysed and categorised by cause. In this study, AAC was defined as a supportrequired airway situation caused by acute respiratory reasons, such as hypoxia, respiratory muscle fatigue, airway obstruction, residual muscular blockage or phrenic nerve dysfunction. The inclusion criteria were general anesthesia, intubation and extubation in the operating room and non-cardiac operations. Patients who had a preoperative tracheal tube or who remained intubated after the operation were excluded. The AAC-caused unplanned reintubation cases were 1:4 matched with control cases, which were randomly selected from the same database using the same selection criteria.

\section{Potential risk factors}

As stated previously, only AAC-caused reintubation patients were included in the case group in this study. Potential risk factors that had been noted in the investigation were classified into patient-specific, anesthetic-specific, operation-specific and outcomerelated. Patient-specific factors included sex, age, body mass index (BMI), American Society of Anesthesiology (ASA) physical status, smoking history, sepsis, heart disease history, cerebral infarction history, asthma or chronic obstructive pulmonary disease (COPD) history, hypertension and diabetes mellitus. Anesthetic-specific factors included Cormack Lehane (CL) grade during intubation, anesthesiologist's seniority, red blood cell
(RBC) infusion, fresh frozen plasma (FFP) infusion, white blood cell (WBC) count, platelet count, red blood cell (RBC) count, alanine aminotransferase (ALT) level, albumin level and creatinine clearance rate (Ccr). Operativespecific factors included the surgical type, fluid load and duration of intubation. The outcome-related variables included postoperative hospital days and ICU days.

The definition of sepsis follows the Third International Consensus Definitions for Sepsis and Septic Shock (Sepsis-3) [6, 7]. Heart disease was defined as previous coronary artery disease, myocardial infarction, heart failure, structural cardiac disease or heart rhythm disease. Fluid load was defined as fluid total input minus total output divided by body weight. The duration of intubation was timed from the first successful intubation to the first completed extubation.

\section{Statistical analysis}

Normally distributed continuous variables are expressed as the mean $\pm \mathrm{SD}$, and non-normally distributed continuous variables ware expressed as the median and interquartile range. Categorical variables are summarised as frequencies and percentages. Univariable analysis was used to compare the differences in potential risk factors between the cases and controls. Categorical variables were compared using chi-squared tests. Continuous variables were first tested for equality of variances using Levene's test, and if the equal variance hypothesis was satisfied, a two-tailed independent t-test was used. The Mann-Whitney $U$ test was used for non-normally distributed or unequal-variance data. Multivariable analysis was conducted to assess the associations between potential risk factors and AAC-caused unplanned reintubation using a multivariable logistic regression model. The variables chosen for the multivariable analysis were based on clinical experience and model fitting statistics. A two-sided $P$-value of $<0.05$ was considered statistically significant. Statistical analyses were conducted using SPSS 19.0 (SPSS Inc. Chicago, IL, USA).

Because the sample size for the cases was identified and a matching ratio larger than 4 would lead to dramatically increased workload with no significant increase in the statistical power, we calculated the statistical power with the established maximum number of cases with a 1:4 matching ratio. The statistical power of this study ranged from 5.26 to $100.00 \%$ based on the potential risk factors. A power $>50 \%$ was achieved for $60.71 \%$ of the potential risk factors.

\section{Results}

From 2014 to 2018 , a total of 189,565 operations were performed in the PUMC Hospital operating room, and 123,068 cases qualified for inclusion according to our criteria (Fig. 1). Among these, 48 cases received 


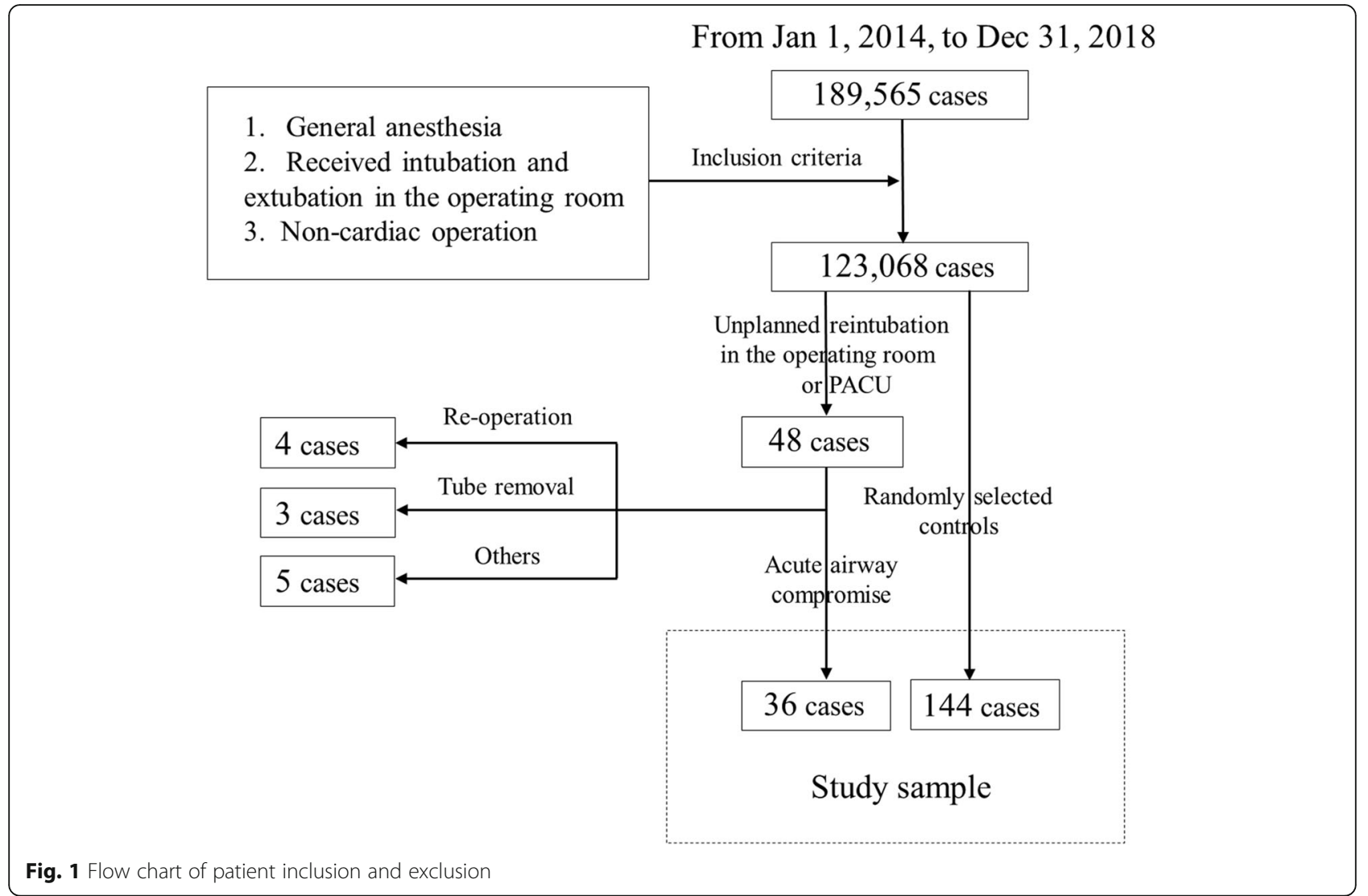

unplanned reintubation in the operating room and $\mathrm{PACU}$, and were categorised into four causes. Four cases were caused by emergent re-operative indications, such as unexpected excessive bleeding after extubation. Three cases were due to unexpected tube removal. Thirty-six cases were due to AAC and were enrolled in the casecontrol study. Five cases were due to other reasons, such as severe haemodynamic instability or neurological complications after a planned extubation. Specific causes of the 36 reintubation cases caused by AAC are shown in Table 1. Airway obstruction including laryngospasm/ bronchospasm, excessive airway secretion, glossocoma, etc. was related to 17 cases. Five cases were possibly caused by respiratory muscle fatigue, for instance, residual muscular blockage. Four cases were associated with phrenic nerve dysfunction and were diagnosed with imaging examination. Five cases were possibly due to other reasons, such as adverse reactions to opioid drugs, acute respiratory distress syndrome (ARDS) or atelectasis. Reasons for five cases cannot be definitively identified.

In this study, the incidence of overall unplanned reintubation was approximately $0.04 \%$, and the incidence of reintubation caused by AAC was approximately $0.03 \%$. All the cases and control groups underwent elective operations with intravenous and inhaled general anesthesia.

For the univariable analysis, the results of potential patient-specific risk factors showed that relative to the controls, sex, age, ASA physical status, sepsis, heart disease history and cerebral infarction history were highly associated with reintubation caused by AAC (Table 2). Statistical results of the potential anesthetic-/operative-

Table 1 Possible causes for the 36 reintubation cases due to AAC

\begin{tabular}{ll}
\hline Possible causes & N (\%) \\
\hline Airway obstruction & $17(47.22)$ \\
Laryngospasm/bronchospasm & $11(30.56)$ \\
Excessive airway secretion & $3(8.33)$ \\
Others & $3(8.33)$ \\
Respiratory muscle fatigue & $5(13.89)$ \\
Residual muscular blockage & $3(8.33)$ \\
Others & $2(5.56)$ \\
Phrenic nerve dysfunction & $4(11.11)$ \\
Others & $5(13.89)$ \\
Unidentified reasons & $5(13.89)$ \\
\hline
\end{tabular}

$A A C$ acute airway compromise 
Table 2 Patient-specific potential risk factors for unplanned reintubation caused by AAC

\begin{tabular}{|c|c|c|c|c|}
\hline Variables & UR $(n=36)$ & Non-UR $(n=144)$ & OR/Mean difference $(95 \% \mathrm{Cl})$ & $P$-value \\
\hline Sex [n (\%)] & & & & $0.039^{*}$ \\
\hline Male & $17(47.22)$ & $42(29.17)$ & $2.17(1.03$ to 4.58$)$ & \\
\hline Female & 19(52.78) & 102(70.83) & & \\
\hline \multicolumn{5}{|l|}{ Age (yr) [n (\%)] } \\
\hline Mean & $59.26 \pm 19.25$ & $46.07 \pm 15.58$ & & $<0.001^{\#}$ \\
\hline$>65$ & 17(47.22) & 14(9.72) & 8.33(3.53 to 19.61$)$ & $<0.001^{*}$ \\
\hline$\leq 65$ & 19(52.78) & 130(90.28) & & \\
\hline BMI $\left(\mathbf{k g ~ m}^{-2}\right)$ & $24.71 \pm 4.45$ & $23.69 \pm 3.84$ & $1.01(-0.45$ to 2.47$)$ & $0.172^{\#}$ \\
\hline ASA [n (\%)] & & & & $<0.001^{*}$ \\
\hline 1 & $5(13.89)$ & $61(42.36)$ & & \\
\hline 2 & $22(61.11)$ & $77(53.47)$ & $3.49(1.25$ to 9.74$)$ & 0.017 \\
\hline 3 & $9(25.00)$ & $6(4.17)$ & $18.30(4.61$ to 72.58$)$ & $<0.001$ \\
\hline Smoking history [n (\%)] & & & & $0.192^{*}$ \\
\hline Yes & $10(27.78)$ & $26(18.06)$ & $1.75(0.75$ to 4.07$)$ & \\
\hline No & $26(72.22)$ & 118(81.94) & & \\
\hline Sepsis [n (\%)] & & & & $0.039^{\wedge}$ \\
\hline Yes & $2(5.56)$ & $0(0.00)$ & - & \\
\hline No & $34(94.44)$ & 144(100.00) & & \\
\hline Heart disease history [n (\%)] & & & & $0.002^{*}$ \\
\hline Yes & $9(25.00)$ & 10(6.94) & $4.46(1.66$ to 12.05$)$ & \\
\hline No & $27(75.00)$ & 134(93.06) & & \\
\hline Cerebral infarction history [n (\%)] & & & & $<0.001^{*}$ \\
\hline Yes & $8(22.22 \%)$ & $2(1.39 \%)$ & $20.41(4.08$ to 100.00$)$ & \\
\hline No & 28(77.78\%) & 142(98.61\%) & & \\
\hline Asthma/COPD history [n (\%)] & & & & $0.257^{*}$ \\
\hline Yes & $2(5.56)$ & $3(2.08)$ & $2.76(0.44$ to 17.24$)$ & \\
\hline No & $34(94.44)$ & 141(97.92) & & \\
\hline Hypertension [n (\%)] & & & & $0.069^{*}$ \\
\hline Yes & 13(36.11) & $31(21.53)$ & $2.06(0.94$ to 4.52$)$ & \\
\hline No & 23(63.89) & 113(78.47) & & \\
\hline Diabetes mellitus [n (\%)] & & & & $0.799^{*}$ \\
\hline Yes & $3(8.33)$ & 14(9.72) & $0.84(0.23$ to 3.11$)$ & \\
\hline No & 33(91.67) & 130(90.28) & & \\
\hline
\end{tabular}

$A A C$ acute airway compromise, UR unplanned reintubation, $O R$ odds ratio, $C l$ confidence interval, $B M I$ body mass index

${ }^{*}$ Chi-square test

"Two-tailed independent t-test

${ }^{\wedge}$ Fisher's exact test, odds ratio cannot be estimated due to the zero event in the control group

specific risk factors and outcome-related variables revealed that patients with $\mathrm{CL}$ grade 3, high WBC counts, poor Ccrs, thoracic surgery, FFP infusion, increased fluid load and long intubation time were more likely to undergo AAC-caused reintubation (Table 3). Longer postoperative hospital and ICU stays were also associated with AAC-caused reintubation (Table 3).

The multivariable analysis demonstrated that age $>65$ yrs. $(\mathrm{OR}=7.50,95 \%$ CI $2.47-22.81, P<0.001)$, ASA physical status $3(\mathrm{OR}=6.51,95 \% \mathrm{CI} 1.18-35.92, P=$ $0.032)$, head-neck surgery $(\mathrm{OR}=4.94,95 \%$ CI 1.33 $18.36, P=0.017)$ or thoracic surgery $(\mathrm{OR}=12.56,95 \% \mathrm{CI}$ 2.93-53.90, $P<0.001$ ), and fluid load $\geq 20 \mathrm{ml} \mathrm{kg}^{-1}$ (OR = $3.04,95 \%$ CI $1.16-7.99, P=0.024)$ were risk factors for reintubation due to AAC (Table 4).

The receiver operating characteristic (ROC) curve was obtained using the logistic regression model (Fig. 2). The area under the curve (AUC) was 0.842 
Table 3 Anesthetic-/operative-specific potential risk factors and prognosis-related variables for unplanned reintubation caused by AAC

\begin{tabular}{|c|c|c|c|c|}
\hline Variables & UR $(n=36)$ & Non-UR $(n=144)$ & OR/Mean difference $(95 \% \mathrm{Cl})$ & $P$ value \\
\hline$\overline{\mathrm{CL} \text { grade }[\mathrm{n}(\%)]}$ & & & & $0.002^{*}$ \\
\hline 1 & 19(52.78) & 102(70.83) & & \\
\hline 2 & $9(25.00)$ & $36(25.00)$ & $1.34(0.56$ to 3.23$)$ & 0.512 \\
\hline 3 & $6(16.67)$ & $3(2.08)$ & $10.74(2.47$ to 46.69$)$ & 0.002 \\
\hline Laryngeal mask & $2(5.56)$ & $3(2.08)$ & $3.58(0.56$ to 22.88$)$ & 0.178 \\
\hline Anesthesiologist seniority of (yr) [n (\%)] & & & & $0.879^{*}$ \\
\hline$>10$ & $21(58.33)$ & $86(59.72)$ & $0.94(0.45$ to 1.98$)$ & \\
\hline$\leq 10$ & 15(41.67) & $58(40.28)$ & & \\
\hline Surgical type [n (\%)] & & & & $<0.001^{*}$ \\
\hline Head and neck & $12(33.33)$ & $40(27.78)$ & $2.01(0.72$ to 5.60$)$ & 0.180 \\
\hline Thoracic & 12(33.33) & $10(6.94)$ & $8.06(2.54$ to 25.58$)$ & $<0.001$ \\
\hline Laparoscopic & $5(13.89)$ & $47(32.64)$ & $0.71(0.21$ to 2.41$)$ & 0.588 \\
\hline Others & $7(19.44)$ & $47(32.64)$ & & \\
\hline RBC infusion [n (\%)] & & & & $0.206^{*}$ \\
\hline Yes & $3(8.33)$ & $5(3.47)$ & $2.53(0.57$ to 1.11$)$ & \\
\hline No & $33(91.67)$ & 139(96.53) & & \\
\hline FFP infusion [n (\%)] & & & & $<0.001^{*}$ \\
\hline Yes & $5(13.89)$ & $1(0.69)$ & 23.07(2.60 to 204.42) & \\
\hline No & $31(86.11)$ & 143(99.31) & & \\
\hline Fluid load ( $\left.\mathrm{ml} \mathrm{kg}^{-1}\right)$ [n (\%)] & & & & $0.009^{*}$ \\
\hline$<20$ & 14(38.89) & $96(66.67)$ & & \\
\hline $20 \sim 40$ & $18(50.00)$ & $40(27.78)$ & $3.09(1.40$ to 6.80$)$ & 0.005 \\
\hline$>40$ & $4(11.11)$ & $8(5.55)$ & $3.43(0.91$ to 12.90$)$ & 0.068 \\
\hline Intubation duration (min)(IQR) & $139.5(104.2,266.0)$ & $132.0(83.5,189.5)$ & $52.13(3.63$ to 100.64$)$ & $0.049^{+}$ \\
\hline WBC count $\left(\times 10^{9} / \mathrm{L}\right)$ & $7.35 \pm 2.80$ & $6.26 \pm 1.96$ & $1.08(0.29$ to 1.88$)$ & $0.008^{\#}$ \\
\hline PLT count $\left(\times 10^{9} / \mathrm{L}\right)$ & $251.08 \pm 80.21$ & $231.87 \pm 66.75$ & $19.22(-6.38$ to 44.81$)$ & $0.140^{\#}$ \\
\hline RBC count $\left(\times 10^{12} / \mathrm{L}\right)$ & $4.49 \pm 0.59$ & $4.47 \pm 0.49$ & $0.02(-0.17$ to 0.20$)$ & $0.868^{\#}$ \\
\hline ALT (U/L) & $20.39 \pm 12.30$ & $23.13 \pm 28.34$ & $0.65(0.14$ to 3.03$)$ & $0.573^{\#}$ \\
\hline ALB $(g / L)$ & $42.08 \pm 4.37$ & $43.58 \pm 4.57$ & $-1.50(-3.16$ to 0.17$)$ & $0.079^{\#}$ \\
\hline \multicolumn{5}{|l|}{$\operatorname{Ccr}(\mathrm{ml} / \mathrm{min})[\mathrm{n}(\%)]$} \\
\hline Mean & $81.03 \pm 28.83$ & $102.62 \pm 29.04$ & & $<0.001^{\#}$ \\
\hline$<70$ & 14(38.89) & 14(9.72) & $5.92(2.48$ to 14.08$)$ & $<0.001^{*}$ \\
\hline$\geq 70$ & $22(61.11)$ & $130(90.28)$ & & \\
\hline Postoperative hospital days (IQR) & $8.5(4.0$ to 12.0$)$ & $4.0(2.0$ to 7.0$)$ & $5.26(1.57$ to 8.95$)$ & $<0.001^{+}$ \\
\hline Postoperative ICU days (IQR) & $1.0(0.0$ to 5.0$)$ & $0.0(0.0$ to 0.0$)$ & $3.94(1.69$ to 6.18$)$ & $<0.001^{+}$ \\
\hline
\end{tabular}

$A A C$ acute airway compromise, UR unplanned reintubation, $O R$ odds ratio, $C l$ confidence interval, $C L$ Cormack Lehane, $R B C$ red blood cell, $F F P$ fresh frozen plasma, $I Q R$ interquartile range, WBC white blood cell, PLT platelets, $A L T$ alanine aminotransferase, $A L B$ albumin, $C C r$ creatinine clearance rate, ICU intensive care unit

${ }^{*}$ Chi-square test

"Two-tailed independent t-test

${ }^{+}$Mann-Whitney U test

(95\% CI 0.759-0.925), and the best cut-off point of this model was determined to correspond to a predicted probability of AAC-caused reintubation of 0.148 , giving a specificity of $83.3 \%$ and a sensitivity of $73.6 \%$.

\section{Discussion}

Reintubation is required for various reasons [3]. Lin P H and colleagues reported that reintubation cases due to accidental removal or self-removal of the tracheal tube 
Table 4 Multivariable regression of potential risk factors associated with unplanned reintubation caused by AAC

\begin{tabular}{clll}
\hline Variables & OR & $\mathbf{9 5 \% ~ C l}$ & $\boldsymbol{P}$-value \\
\hline Age $>$ 65 & 7.50 & 2.47 to 22.81 & $<0.001$ \\
Male sex & 1.95 & 0.74 to 5.15 & 0.178 \\
ASA Class & & & \\
ASA1 & & & \\
ASA2 & 1.77 & 0.56 to 5.54 & 0.331 \\
ASA3 & 6.51 & 1.18 to 35.92 & 0.032
\end{tabular}

Surgery type

Others

\begin{tabular}{llll} 
Head and neck & 4.94 & 1.33 to 18.36 & 0.017 \\
Thoracic & 12.56 & 2.93 to 53.90 & $<0.001$ \\
Laparoscopic & 1.69 & 0.39 to 7.25 & 0.480 \\
Fluid load $\geq \mathbf{2 0} \mathbf{~ m l ~ k g}^{-1}$ & 3.04 & 1.16 to 7.99 & 0.024 \\
\hline
\end{tabular}

$A A C$ acute airway compromise, $O R$ odds ratio, $\mathrm{Cl}$ confidence interval, $A S A$ American Society of Anesthesiology

both had distinct risk factors and prognoses [8]. In this study, we classified the unplanned reintubation cases by cause, excluded the non-respiratory cases, and mainly focused on AAC-caused reintubation after general anesthesia since the postoperative respiratory compromise cases stood out as the majority (36/48, 75.0\%).

Based on our results, age $>65$ yrs. and ASA physical status 3 were identified as highly associated with unplanned reintubation caused by AAC. This result was in accordance with previous results that noted that advanced age and ASA physical status $\geq 3$ should be considered independent risk factors for postoperative

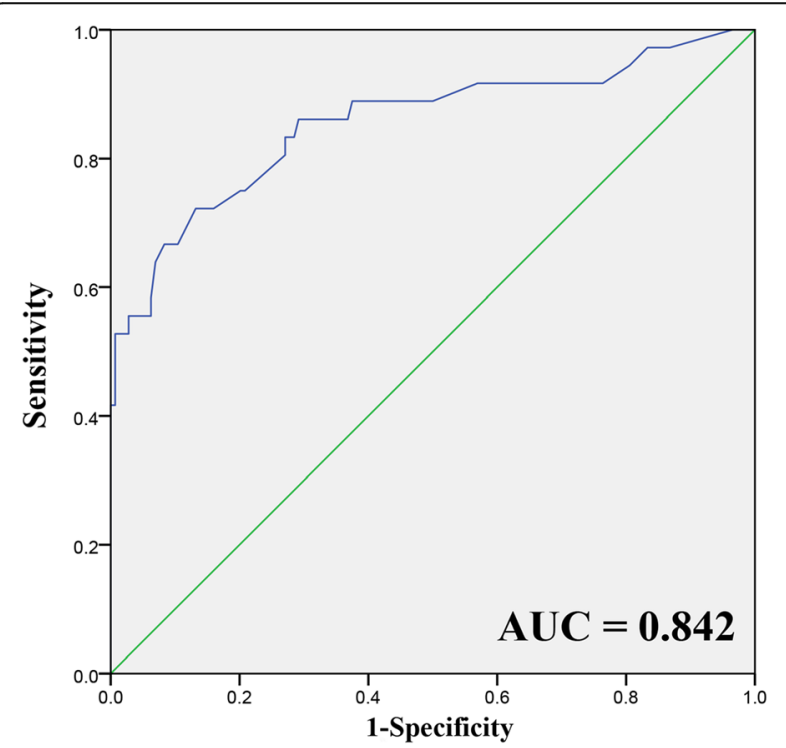

Fig. 2 ROC curve of the logistic regression model. AUC = area under the curve respiratory failure $[9,10]$. Age $\geq 65$ years was also shown to be an important risk factor for failed extubation in ICU patients [11]. For comorbidities, preoperative sepsis was found to have a positive association with reintubation due to $\mathrm{AAC}$, which agrees with the previous literature $[2,12]$. Heart disease history and cerebral infarction history were shown to be related to AAC-caused unplanned reintubation in the univariable analysis. Heart disease history is in line with previous results that found that patients with underlying chronic cardiac disease are at a high risk for extubation failure [1]. However, some studies reported no increased risk of reintubation in patients with comorbidities such as heart diseases [13], cerebrovascular accidents or central nervous system (CNS) diseases [14, 15]. For other comorbidities, a largescale prospective study suggested that hypertension and insulin-required diabetes mellitus were independent predictors of unanticipated early postoperative intubation [2]. However, in this study, hypertension demonstrated a trend of increased risk in only the univariable analysis, although the result was not statistically significant. Stratifying patients by medication- or insulin-required diabetes mellitus may obtain more accurate results.

A multitude of studies have reported that COPD is highly associated with reintubation [1, 2, 14-17]. It was believed that COPD manifested as narrowing of the small airways, leading to an increase in breathing effort and exacerbating respiratory diaphragm muscle fatigue [18]. One possible reason that the results obtained from this study were not in accordance with previous reports is that in the PUMC Hospital, most moderate or severe COPD patients were sent back to the ICU straight after the operations and were thus excluded from the study.

To the best of our knowledge, no previous study has assessed the association between CL grade and reintubation. CL grading is usually used as a predictor for difficult intubation $[19,20]$. In this study, CL grading was significant in the univariable analysis. We suspect that the crowded pharyngeal structure contributed to the collapsibility of the airway. Regarding laboratory results, a $\mathrm{Ccr}<70 \mathrm{ml} / \mathrm{min}$ was demonstrated to be associated with AAC-caused unplanned reintubation in the univariable analysis. Numerous studies have concluded that chronic kidney disease [14] and renal insufficiency $[2,11,17]$ are significant risk factors for reintubation. Although increased WBC counts were identified to be significant in the univariable analysis, they were more likely to be the result of confounding effects, rather than true associations. Hypoalbuminemia was also suggested to be highly associated with postoperative reintubation in some previous studies [11, 17]. However, such a result was not observed in this study.

A number of studies have reported the association between transfusion or RBC transfusion and reintubation 
[2]. To our knowledge, no previous study has assessed FFP transfusion as a potential risk factor for reintubation. Notably, we found FFP transfusion to be significant in the univariable analysis. Although reintubation patients could not be diagnosed with acute ARDS due to the absence of a blood-gas test, several studies have reported the relationship between FFP transfusion and ARDS [21]. Neto and colleagues found that perioperative FFP transfusion increased the risk of postoperative ARDS [22]. Thus, FFP transfusion may be correlated with ARDS and reintubation after operation. RBC transfusion was not identified as an independent risk factor, consistent with the result from Acheampong D and colleagues [11]. A fluid load $\geq 20 \mathrm{ml} \mathrm{kg}^{-1}$ was revealed as a risk factor in this study; however, other studies found that fluid balance or overload was not a significant risk factor, possibly due to the different definitions of fluid load $[15,23]$. There is evidence that an extensive infusion of fluid during an operation results in pulmonary edema and pneumonia [24], which may be correlated with unplanned reintubation.

For the operative-specific factors, head-neck surgery and thoracic surgery were identified as significant risk factors; this result is similar to those in previous reports $[15,16]$. Of all the unplanned reintubated cases, four thoracic patients were ultrasonically diagnosed with phrenic nerve injury, which is an iatrogenic complication following thoracic and cardiac surgery, with an overall incidence ranging from 1 to $11 \%[25,26]$. In PUMC Hospital, all patients undergoing cardiac operations were extubated routinely in the ICU, therefore, all cardiac cases were excluded from the investigation.

In this study, the incidence rate of reintubation was low compared with that in the previous literature [13, 14]. There are mainly four feasible reasons for this variation in the results. First, all the anesthesiologists were trained by the same protocol despite seniority [27]. Second, extubation was routinely conducted by two anesthesiologists, and both the attending and resident doctors were responsible for the case. Third, most critical patients were sent back to the ICU after their operation, which also explained why there were no ASA physical status 4 or 5 patients in the study. Finally, although unplanned reintubation is mandatory to report in the adverse event reporting system, we suspect that there may have been some missing cases.

A small sample size was the major limitation for this study. As identified in the power estimate that was included in the statistical analysis, $60.71 \%$ of the potential risk factors had $>50 \%$ power, and the incidence of reintubation due to AAC was only $0.03 \%$. This severely underpowered analysis may lead to false-negative results. Therefore, the potential factors that were found negative in this study will not necessarily be unrelated to the reintubation caused by AAC. Moreover, sepsis should be considered as an important risk factor for reintubation $[2,12]$, it also revealed statistical significance in the univariable analysis. However, due to the very limited sample size, only two patients were found in the case group while none was found in the control group. The zero event prevented us from including sepsis in the multivariable regression model. A larger sample size may be needed to verify these associations adequately. There were other limitations of this study. For instance, as this was a retrospective case-control study, there might be potential confounders that have causal associations with unplanned reintubation and are unbalanced between the case and control groups, therefore resulting in confounding effects. In addition, data on other potential risk factors, such as respiratory tract infection or hypothermia, which were considered significant in previous studies $[15,17]$, were not included in this study due to the limitation of the recording system. Prospective, multicenter studies with larger sample sizes and fewer untreated confounders are required to further validate the current conclusions.

One strength of this study was that it specified the cause of reintubation. Therefore, the evaluation of the risk factors had increased accuracy. Additionally, for the first time, we revealed that FFP transfusion and CL grades were significantly related to unplanned reintubation. Finally, all the cases and controls received a combination of intravenous and inhaled anesthesia; to some extent, we prevented the anesthetic method from acting as a confounding factor.

Here, we have attempted to identify risk factors for postoperative unplanned reintubation caused by AAC to prevent unplanned reintubation after general anesthesia. Thus, minimizing patient risk factors, staying alert and making judicious decisions are essential to improve surgical prognoses.

\section{Abbreviations \\ AAC: Acute airway compromise; PUMC: Peking Union Medical College; ASA: American Society of Anesthesiology; BMI: Body mass index; COPD: Obstructive pulmonary disease; CL: Cormack Lehane; ALT: Alanine aminotransferase; WBC: White blood cell; RBC: Red blood cell; ALB: Albumin; Ccr: Creatinine clearance rate; PLT: Platelets; FFP: Fresh frozen plasma; ICU: Intensive care unit; ARDS: Acute respiratory distress syndrome; IQR: Interquartile range}

Acknowledgements

Assistance with the study: We would like to thank Dr. Luxi Meng and Dr. Xuemei Feng for their valuable consultations.

\section{Authors' contributions}

SC: data collection, writing the article. YZ: analysis and interpretation. LC: data collection. LS: conception and design, analysis and interpretation, critical revision of the article and obtaining funding. $\mathrm{YH}$ : critical revision of the article and obtaining funding. All authors have read and approved the manuscript. 


\section{Funding}

CAMS Innovation Fund for Medical Sciences (CIFMS) (2016-I2M-3-024).

\section{Availability of data and materials}

The datasets generated and analyzed during the current study are available from the corresponding author on reasonable request.

\section{Ethics approval and consent to participate}

This investigation was a single-center retrospective, case-control study approved by the Peking Union Medical College (PUMC) Hospital Institutional Review Board (S-K745, April 25th, 2019). All the data were collected from the adverse-event reporting system, the anesthetic recording system and Hospital Information System of PUMC Hospital. No written informed consent was obtained from participants.

\section{Consent for publication}

The authors declare consent for publication, and there are no individual identifying data.

\section{Competing interests}

The authors declare no competing interests.

\section{Author details}

'Department of Anesthesiology, Peking Union Medical College Hospital, Chinese Academy of Medical Science \& Peking Union Medical College, Beijing 100730, China. ${ }^{2}$ Medical Research Center, Peking Union Medical College Hospital, Chinese Academy of Medical Science \& Peking Union Medical College, Beijing 100730, China.

Received: 28 July 2020 Accepted: 5 January 2021

Published online: 12 January 2021

\section{References}

1. Thille AW, Harrois A, Schortgen F, Brun-Buisson C, Brochard L. Outcomes of extubation failure in medical intensive care unit patients. Crit Care Med. 2011:39(12):2612-8.

2. Ramachandran SK, Nafiu OO, Ghaferi AA, Tremper KK, Shanks A, Kheterpal S. Independent predictors and outcomes of unanticipated early postoperative tracheal intubation after nonemergent, noncardiac surgery. Anesthesiology. 2011;115(1):44-53.

3. Chinachoti T, Poopipatpab S, Buranatrevedhya S, Taratarnkoolwatana K, Werawataganon T, Jantorn P. The Thai anesthesia incident monitoring study (Thai AIMS) of post anesthetic reintubation: an analysis of 184 incident reports. J Med Assoc Thail. 2008;91(11):1706-13.

4. Jaber S, Quintard H, Cinotti R, Asehnoune K, Arnal J, Guitton C, PaugamBurtz C, Abback P, Dessap AM, Lakhal K, et al. Risk factors and outcomes for airway failure versus non-airway failure in the intensive care unit: a multicenter observational study of 1514 extubation procedures. Crit Care. 2018:22:236.

5. Fujii E, Fujino K, Tanaka-Mizuno S, Eguchi Y. Variation of Risk Factors for Cause-Specific Reintubation: A Preliminary Study. Can Respir J. 2018;2018: 3654251.

6. Singer M, Deutschman CS, Seymour CW, Shankar-Hari M, Annane D, Bauer M, Bellomo R, Bernard GR, Chiche JD, Coopersmith CM, et al. The third international consensus definitions for Sepsis and septic shock (Sepsis-3). JAMA. 2016;315(8):801-10.

7. Seymour CW, Liu VX, Iwashyna TJ, Brunkhorst FM, Rea TD, Scherag A, Rubenfeld G, Kahn JM, Shankar-Hari M, Singer M, et al. Assessment of clinical criteria for Sepsis: for the third international consensus definitions for Sepsis and septic shock (Sepsis-3). JAMA. 2016;315(8):762-74.

8. Lin P, Chen C, Chiu H, Tai H, Lee DL, Lai R. Outcomes of unplanned extubation in ordinary ward are similar to those in intensive care unit. Medicine (Baltimore). 2019:98(11):e14841.

9. Attaallah AF, Vallejo MC, Elzamzamy OM, Mueller MG, Eller WS. Perioperative risk factors for postoperative respiratory failure. J Perioper Pract. 2019;29(3):49-53.

10. Acheampong D, Guerrier S, Lavarias $V$, Pechman D, Mills C, Inabnet WB, Leitman IM. Unplanned postoperative reintubation following general and vascular surgical procedures: outcomes and risk factors. Ann Med Surg (Lond). 2019;33:40-3.
11. Cheng A-C, Cheng K-C, Chen C-M, Hsing S-C, Sung M-Y. The outcome and predictors of failed extubation in intensive care patients - the elderly is an important predictor. Int J Gerontol. 2011;5(4):206-11.

12. Hua M, Brady JE, Li G. A scoring system to predict unplanned intubation in patients having undergone major surgical procedures. Anesth Analg. 2012; 115(1):88-94.

13. Suraseranivong $R$, Krairit $O$, Theerawit $P$, Sutherasan $Y$. Association between age-related factors and extubation failure in elderly patients. PLoS One. 2018;13(11):e0207628

14. Brovman EY, Steen TL, Urman RD. Associated risk factors and complications in vascular surgery patients requiring unplanned postoperative reintubation. J Cardiothorac and Vasc Anesth. 2017;31(2):554-61.

15. Lin HT, Ting PC, Chang WY, Yang MW, Chang CJ, Chou AH. Predictive risk index and prognosis of postoperative reintubation after planned extubation during general anesthesia: a single-center retrospective casecontrolled study in Taiwan from 2005 to 2009. Acta Anaesthesiol Taiwanica. 2013;51(1):3-9.

16. Ting PC, Chou AH, Yang MW, Ho AC, Chang CJ, Chang SC. Postoperative reintubation after planned extubation: a review of 137,866 general anesthetics from 2005 to 2007 in a medical Center of Taiwan. Acta Anaesthesiol Taiwanica. 2010;48(4):167-71.

17. Rujirojindakul P, Geater A, Mcneil E, Vasinanukorn P, Prathep S, Asim W, Naklongdee J. Risk factors for reintubation in the post-anaesthetic care unit: a case-control study. Br J Anaesth. 2012;109(4):636-42.

18. Lemaire F, Jeanlouis T, Cinotti L, Giotto G, Abrouk F, Steg G, Macquinmavier I, Zapol WM. Acute left ventricular dysfunction during unsuccessful weaning from mechanical ventilation. Anesthesiology. 1988;69(2):171-9.

19. Mathangi K, Mathews J, Mathangi C. Assessment of perioperative difficult airway among undiagnosed obstructive sleep apnoea patients undergoing elective surgery: a prospective cohort study. Indian J Anaesth. 2018;62(7):538.

20. Andrade RG, Lima BL, Lopes DK, Filho RO, Lima LC, Couceiro TC. Difficult laryngoscopy and tracheal intubation: observational study. Braz J Anesthesiol. 2018;68(2):168-73.

21. Jia X, Saeed M, Mark RG, Malhotra A, Talmor DS. Risk factors for acute lung injury and acute respiratory distress syndrome in patients mechanically ventilated $>48$ hours in the ICU. Crit Care Med. 2006:34

22. Neto AS, Juffermans NP, Hemmes SN, Barbas CS, Beiderlinden M, Fernandezbustamante A, Futier E, Gajic O, Jaber S, Kozian A, et al. Interaction between peri-operative blood transfusion, tidal volume, airway pressure and postoperative ARDS: an individual patient data meta-analysis. Ann Transl Med. 2018;6(2):23.

23. Michetti CP, Griffen MM, Teicher EJ, Rodriguez J, Seoudi H, Liu C, Lita E, Newcomb AB. FRIEND or FOE: a prospective evaluation of risk factors for reintubation in surgical and trauma patients. Am J Surg. 2018;216(6): 1056-62.

24. Hahn RG. Adverse effects of crystalloid and colloid fluids. Anaesthesiol Intensive Ther. 2017:49(4):303-8.

25. Markand ON, Moorthy S, Mahomed Y, King RD, Brown JW. Postoperative phrenic nerve palsy in patients with open-heart surgery. Ann Thorac Surg. 1985;39(1):68-73.

26. Muhyieddeen K, Forouzandeh F. Diaphragmatic paralysis after cardiac surgery. J Am Coll Cardiol. 2012;59(18).

27. Cavallone LF, Vannucci A. Extubation of the difficult airway and Extubation failure. Anesth Analg. 2013;116(2):368-83.

\section{Publisher's Note}

Springer Nature remains neutral with regard to jurisdictional claims in published maps and institutional affiliations. 